\title{
Tres momentos iniciales en la vida política de Manuel Azaña
}

JOSÉ GILABERT ORTEGA

\section{INTRODUCCIÓN}

Ambición, castigo, verdad, desconocido, inteligencia, soledad, tragedia, vocación, imposible. Rara es la obra que se haya escrito en torno a Manuel Azaña Díaz que no vaya acompañado de un título o subtítulo, que como los calificativos anteriores, nos indiquen ya de antemano alguno de los rasgos que marcan su trayectoria vital.

Al cumplirse cincuenta años de la muerte de Manuel Azaña, al igual que sucedió en 1980 con ocasión de su centenario, no han faltado trabajos escritos o documentales televisivos que den a conocer diversos aspectos de la vida y obra del que fuera último presidente de la II República española.

El presente artículo tiene por objeto indagar sobre lo que hemos dado en llamar «Tres momentos iniciales en la vida política de Manuel Azaña». Momentos, que como a continuación veremos, tendrán como «telón de fondo» su actitud ante el Estado y los problemas derivados de la Constitución de 1876 y la republicana de 1931 .

El año 1911 será el primero de estos momentos. Azaña pronunciará en la Casa del Pueblo de su villa natal una conferencia que bajo el título «El problema español» marcará, en opinión de Juan Marichal, «el comienzo público de una trayectoria ideológica, que no empezó con la guerra ni siquiera con la proclamación de la República». ${ }^{1}$ La cuestión principal de la conferencia de 1911, como veremos, es la intangibilidad entre la democracia y la cultura. La influencia de Unamuno, Ortega y 
Costa, transpirará por todo el contenido de esta obra de juventud. Queda muy poco tiempo para que Azaña viaje a Francia, participe en la fundación de la Liga de Educación Política, e ingrese en el Partido Reformista de Melquiades Álvarez.

El segundo período inicial, tiene lugar con la instauración de la dictadura de Primo de Rivera. Azaña, desengañado del reformismo, iniciará un nuevo derrotero político. En 1924 saldrá a la luz su manifiesto «Apelación a la República», en el cual trata de indicar la necesidad de la institución parlamentaria como garantía de la libertad. En 1925 fundará, con José Giral, el partido Acción Republicana, que jugará un importantísimo papel en los primeros años de la II República. Pero a pesar de este importante paso, los años de dictadura serán para Azaña un tiempo más para la reflexión intelectual y la composición literaria que para la acción netamente política.

El último de estos momentos, coincidirá con la proclamación de la II República. Azaña, miembro del Comité Revolucionario, formará parte como Ministro de la Guerra en el Gobierno Provisional del nuevo régimen, se mantendrá en ese puesto tras las primeras elecciones a Cortes, hasta alcanzar la presidencia del Gobierno en octubre de 1931 dada la dimisión de Alcalá Zamora. Su actitud, a través de sus diarios, ante la nueva Constitución que ha de dar cobertura jurídica al nuevo Estado nacido el 14 de abril, será el objeto principal de nuestra atención. 


\section{1911. EL PROBLEMA ESPAÑOL}

La obra que ahora comentamos es el primer texto de Manuel Azaña, fuera de su producción periodística anterior y de sus obras jurídicas de juventud, ${ }^{2}$ donde el autor exponga sus opiniones y el esbozo de un programa político para el futuro. Tomará para tal menester el modelo político británico, al igual que Cánovas curiosamente, si bien es cierto que lo escribirá poco antes de marchar a Francia donde sus instituciones políticas habrán de ejercer en él una extraordinaria influencia. ${ }^{3}$

Invitado por los socialistas de Alcalá de Henares para pronunciar una conferencia que formara parte del conjunto de actos culturales que siguieron a la inauguración de la Casa del Pueblo en la mencionada ciudad madrileña, Azaña elegirá, igual que Macías Picavea había hecho en 1891 para una de sus más famosas obras, el título de «El problema español». Leída el 4 de febrero de 1911, cuatro días después tendrá lugar el fallecimiento de Joaquín Costa. Con este trabajo le tributa un buen homenaje.

La influencia de Costa puede apreciarse sensiblemente en esta obra. Por un lado se aborda la cuestión, muy en boga entonces, en torno a la «europerización de España», en este sentido Azaña escribe:

«El problema español, ¿podrá España incorporarse a la corriente general de la civilización europea? la especialidad consiste en que ningún otro pueblo se ha hecho pregunta semejante. $\rangle^{4}$

Por otro lado la importancia dada por Azaña a la cuestión educativa, al considerarla como motor fundamental de cambio y reforma. Habrán de pasar algunos años, entre 1921 a 1923, para que Azaña formule su crítica a Costa, sin perder por ello su aprecio por la figura de Graus. Azaña, dice Raúl Morodo, «intuye el carácter tradicionalista del costismo: soluciones arbitristas, y en el fondo, conservadoras, reformar el establishmet, pero, en definitiva, no cambiarlo». 5

Pero, volvamos a 1911. En «El problema español» Azaña nos ofrece todo un conjunto de ideas para la transformación de España en un 
avanzado Estado moderno, un Estado moderno que sorprendentemente «es tan absoluto y absorvente como el antiguo Estado de las monarquías puras». ${ }^{6}$ Sin entrar a valorar los peligros del poder omnimodo de ese Estado, ni siquiera la forma que el mismo debe adoptar, Azaña creerá que:

«Pese a todos sus defectos de organización, con su ceguedad y su parsimonia, es del único Dios de quien podemos esperar que ese milagro (la justicia) se verifique. ¿De quién si no, vamos a recibir la justicia.» ${ }^{7}$

En el Estado están sus esperanzas, en la sociedad sus recelos. Apenas comenzado su discurso proclamará:

«Es preciso reconstruir la conciencia nacional para que el solar patrio deje de ser un campo de desolación... Si la vida española carece de una orientación colectiva, ¿cómo podrá funcionar el mecanismo político construido para servirla. ${ }^{8}$

Esta «orientación colectiva», creemos, que en Azaña se expresa en la búsqueda de soluciones democráticas y en la confianza en la democracia:

«Entiendo que la democracia (al igual que Azcárate) no es una clase que haya de sobreponerse a las demás, ni un procedimiento más o menos violento de llevar estas o las otras ideas y sí esta fuerza nueva, este nuevo principio, este nuevo sentido del Derecho y de la vida política, más amplio, más universal, más humano, que han encarnado en la vida de los pueblos después de haber ido madurando en la esfera del pensamiento y que está hoy inspirando a las sociedades modernas». ${ }^{9}$

El régimen de la Restauración, sobre el cual escribe Azaña, se había basado en los principios típicos del liberalismo político, y precisamente son estos los primeros en «traicionarse» a través del continuo fraude electoral, con lo que se desnaturaliza la construcción de la democracia en España. A raíz de esto Azaña dirá:

"Cuando no hemos conocido todavía el mecanismo de una democracia abobinamos de ella... y sobre ella echamos la culpa de nuestro malestar y poca ventura»..$^{10}$

Para Azaña la democracia es una ficción en España, porque ésta para su plasmación en la vida pública necesita de un cuerpo de electo- 
res que sea expresión fiel de la voluntad popular. En España ese cuerpo electoral, que tenga unos intereses y los proteja, es prácticamente inexistente. A propósito de esta situación, Azaña, nos revela su visión:

«No tenemos pueblo organizado; y en esta palabra entramos todos, chicos y grandes, pobres y ricos. Como no hay ideal nacional, vivimos en castas: unas odian, otras temen; unas devoran su furia, otras explotan a los furiosos, y así estamos, arma al brazo, esperando la hora de destrozarnos. $\rangle^{11}$

Su descripción de las instituciones, que sólo conforman una «aparente» democracia, no puede ser más sombría. La institución democrática por excelencia, el Parlamento, nos es así descrito:

«Un escenario de la vanidad y de la nulidad, de la impotencia y de la mojiganga; una costra que encubre una llaga, un lugar donde se dicen frases pomposas, que nadie cree, donde se ejercita la función soberana de disponer de bienes y haciendas, a espaldas de un pueblo ausente y olvidadizo, donde la tarea de aplicar los recursos extraídos del trabajo colectivo se convierten en una francachela, en un desatamiento de todas las codicias, donde el sudor nacional sirve para sostener los vicios y las lujosas vanidades de unos pocos privilegiados. ${ }^{12}$

Los partidos turnantes son objeto de una especial crítica por parte de Azaña:

«Nuestros partidos de gobierno no son más que una cuantas familias que viven acampadas sobre el país, presidiendo esta orgía, transmitiéndose de generación en generación, de nulidad en nulidad, los grandes puestos, con una impudicia execrable, que toman en boca los nombres de patria, justicia, y libertad para sostener la mentira sin que se quemen sus labios y que incurren a sabiendas en la más tremenda responsabilidad, porque ellos harán justas, y naturales y necesarias las más violentas revanchas que el pueblo cuando despierte puede tomar... Y esto ha sido posible y se mantiene, porque esas clases llamadas directoras no se contentan con su actual usurpación, sino que han tratado siempre de conservarla para mañana y han matado todo impulso generoso sembrando el escepticismo y la desconfianza en el corazón del pueblo.» ${ }^{13}$

Ante todo este panorama que Azaña nos ha descrito, su posición para resolver «El problema español» es clara: la participación política. Los hombres de la generación de 1914 apostaron por ella frente al «abstencionismo» del noventa y ocho; Azaña no será una excepción: 
« ¿Democracia hemos dicho? Pues democracia. No caeremos, en la ridícula aprensión de tenerla miedo, restaurémosla, o mejor, implantémosla, arrancándola de sus esenciales formas todas las escrecencias que la desfiguraron. No odiéis ni os apartéis de la política, porque sin ella no nos salvaremos. Si la política es el arte de gobernar un pueblo, hagamos todos política y cuanta más mejor, porque sólo así podremos gobernar a nosotros mismos e impedir que nos desgobiernen otros. $)^{14}$ 


\section{AZAÑA Y LA DICTADURA}

El golpe de Estado del General Primo de Rivera de 1923 supuso el principio del fin de una monarquía y de un régimen que había empezado desde hacía ya varios años atrás, con la disolución de los partidos dinásticos que la habían sustentado, a presentar graves síntomas de descomposición.

Con el advenimiento de la dictadura, será cuando las ideas republicanas vuelvan a cobrar un valor que había caído en franca decadencia tras la amarga experiencia de la I República. Es decir, la República será considerada un modelo de «Estado alternativo» al monárquico de la Restauración, pues aquella ya no tiene sentido tal como la expresaba Melquiades Álvarez:

«Una fuerza más para obligar a la monarquía a seguir las sendas de la democracia y de la modernidad que una meta en sí misma. Y si el rey reconocía ser «el esclavo de la opinión» si reinaba mediante el parlamento elegido sinceramente, no había por qué oponérsele.. ${ }^{15}$

Azaña ante la nueva situación, abandonará definitivamente cualquier posibilidad de progresar "desde dentro», hacia una verdadera democracia. Su abandono del Partido Reformista, en el que venía militando desde varios años atrás, es inmediato. Pocos días después de tener lugar el golpe, en carta dirigida a Melquiades Álvarez, Azaña se daba de baja en el partido, había comenzado así su viraje hacia la República.

La crítica a Melquiades Álvarez por su posición ante la dictadura la mantendrá Azaña durante varios años. A la altura de septiembre de 1931, Azaña escribe en su diario:

«La sesión de las Cortes ha tenido el interés de dejarnos oir a Melquiades Álvarez. Está viejo, y se le ha rajado la voz de tenor; pero conserva muchas facultades. Su discurso ha sido malo. De un moderantismo sin fundamento, con una de cal y tres de arena; lleno de lugares comunes y de expresiones muy manidas, agotadas por él mismo. Sobre todo aparece aumentada su falta de gusto, que siempre fue grande. Y su falta de autoridad, comprometida y perdida en los años de la dictadura, por su ambigua posición. Cuando yo le es- 
cribí, el 17 de septiembre de 1923, invitándole a reunir al Partido Reformista, para adoptar sin reservas la política republicana, y no me hizo caso, Melquiades se jugó y perdió su porvenir. Si entonces hubiera hecho lo que era un clarísimo deber e hicimos otros muchos, Melquiades habría sido el hombre de la República, en vez de serlo Alcalá Zamora. Verdad es que probablemente lo hubiera hecho peor que don Niceto. Hoy está solo don Melquiades. ${ }^{16}$

Más adelante, Azaña vuelve a incidir en la crítica, ahora lo hará de una manera mucho más personalizada:

«Al parecer, Melquiades Álvarez no disimula el enojo que le ha producido mi subida al poder. Melquíades me tuvo diez años en su partido (1913-1923) 'y no supo hacer de mí ni un concejal.» ${ }^{17}$

Su decisión, como hemos dicho será rápida y drástica. Sin embargo continuará a la cabeza de la revista España, la que fundara Ortega en 1915, pero no por mucho tiempo pues en marzo de 1924 esta publicación dejará de salir a la calle. Casi un año después, hacia 1925, Azaña escribe:

"Yo estaba entonces muy desanimado y en desacuerdo con casi todo el mundo, porque casi todo el mundo acataba la dictadura de Primo de Rivera o la encontraba muy buena, sin exceptuar a los escritores y redactores de "El Sol"..» ${ }^{18}$

A pesar de esta adversidad, Azaña seguirá escribiendo para la revista francesa Europe y para la argentina Nosotros. Su último trabajo para España lleva por título «Nuevos partidos, libertades viejas». En él podemos leer:

«La libertad es la condición de la ciudadanía; si la libertad se restringe los hombres de más encandilado civismo podrán ser celosos administradores de un patrimonio, diligentes padres de familia, santos, artistas, lo que quieran; pero no ciudadanos... La libertad ha naufragado en casi toda Europa; comprobemos el suceso, dándole su verdadero nombre, pero a nadie se le hará creer que es libre no siéndolo. Se suspende la ley, que es garantía; no el derecho. Las libertades públicas no son privilegios, ni gracias otorgadas; tienen una base indestructible: el hecho de la conciencia humana... Que los partidos administradores del régimen han muerto, a la vista está. No es menester echarles mucha tierra encima ni alancearlos después de morir. Ya pasaron. Y no es que sus hombres hayan perdido una autoridad dudosa o se haya desvanecido su prestigio; es que los supuestos donde se fundaba su existencia, de los 
que era probanza escrita la Constitución, han resultado falsos. Quedan en pie, con sus principios intactos, el socialismo y el republicanismo. La cuestión de la forma de gobierno volverá a plantearse con el vigor que corresponde a la imposibilidad de todo reformismo. ${ }^{19}$

La idea de la libertad, entumecida por los rigores de la dictadura, es constante en esta etapa de la vida de Manuel Azaña. En 1925 escribe en su ensayo «Democracia y Parlamento»:

«El liberalismo reclama para existir la democracia. Son el alma y el cuerpo en que asiste. Democracia quiere decir que los hombres libres defienden, ejercen, garantizan por sí mismo su propia libertad. Y si no lo hacen, no son libres aunque sean liberales. $\rangle^{20}$

Después de decir estas palabras, Azaña llama la atención en torno a los peligros que acechan a la libertad, o mejor dicho al parlamentarismo como mecanismo político para expresar la libertad. Desde la reacción o desde la modernidad se puede atentar contra la fórmula parlamentaria:

"Que los enemigos de la libertad no vengan a mortificarnos el tímpano con declamaciones antiparlamentarias. Los ataques, más recios cada vez, que estos años se dirigian al Parlamento son de dos órdenes: doctrinal y práctico. Unos atacan al Parlamento porque son enemigos de la libertad, precisamente por lo que el Parlamento tiene de eficaz, de representativo y eficaz. Estos son los de siempre, los secuaces de la reacción absolutista, en todas sus formas, bajo todas sus máscaras... Pero otros, con pretensiones de hombres modernos y a título de modernidad, sin que dejen de llamarse liberales, acumulan sobre el Parlamento los más violentos cargos, mirando sólo a su ineficacia. Contra su omnimodo poder legislativo, aducen su incompetencia técnica; contra los gobiernos salidos de las mayorías, aducen las transacciones de bajo vuelo, las intrigas y las rivalidades personales que se agitan en los choques de los partidos; pensando que el Gobierno ha de ser ante todo celeridad, decisión y tino, demuestran que el Parlamento es dilatorio, irresoluto, ciego... "La cuestión es siempre la misma: querer la libertad o no quererla".." ${ }^{21}$

\section{Creemos que es Manuel Aragón quien mejor define la evolución po- lítica de estos años en Manuel Azaña:}

«Para Azaña, el problema quedaba planteado de este modo: si la monarquía se había transformado en autoritarismo y dictadura, la libertad y la democracia sólo podían ser posibles en la república... Este esquema tan radical, 
históricamente cierto, por lo demás, de 1931 a 1939, era, por ello mismo, revelador de nuestro subdesarrollo político, de nuestra escasa modernidad. La monarquía y la república, en la España de los años treinta, seguían siendo lo que ya habían dejado de ser en Europa desde el siglo pasado: formas de Estado; sin haberse convertido aún en lo que eran en los países civilizados: meras formas de Gobierno. ${ }^{22}$ 


\section{LA REPÚBLICA DE ABRIL}

Las elecciones municipales de abril de 1931, convocadas por el Gobierno Aznar, pusieron fin a la monarquía de Alfonso XIII y conllevaron a la proclamación de la II República española. Azaña entrará a formar parte, como Ministro de la Guerra, en el Gobierno Provisional del nuevo régimen. Por desgracia, sus Memorias Políticas no recogen los primeros meses de su actuación ministerial, pues comienzan a ser escritas el 2 de julio de 1931 .

Sin embargo, sí que podemos conocer su actitud ante los debates parlamentarios surgidos como consecuencia de la elaboración de la nueva Constitución republicana. Una Constitución obra de una Cortes constituyentes elegidas el 28 de junio de 1931 y que en opinión de Carlos María Rama:

«Nunca en la historia de España - si se exceptúan las Cortes de Cádiz de 1812- se ha elegido una asamblea representativa con tanto entusiasmo y poniendo tantas esperanzas en su obra legislativa. ${ }^{23}$

Considerada la elaboración de la Constitución como la obra fundamental de las Cortes de 1931-1933, veamos a continuación las etapas que atravesó para su aprobación y las opiniones de Azaña en cada una de ellas.

En primer lugar el Gobierno Provisional encargó un proyecto, o mejor dicho, un anteproyecto de Constitución a una comisión de juristas de la que formaban parte entre otros, Ossorio y Gallardo, y Adolfo Posada, la cual presentó el 6 de julio de 1931 un texto que constaba de 104 artículos.

Azaña, anotará en su diario con fecha 7 de julio de 1931:

«Acordamos no entrar a fondo en la discusión del anteproyecto de Constitución, puesto que no podemos presentar, dada la hechura del gobierno, un texto que aceptamos todos. Irá a la Comisión de las Cortes, con todos los votos particulares que han formulado en la junta redactora. $)^{24}$ 
Los avatares políticos de la época hicieron que este anteproyecto decayese en su tramitación parlamentaria. Ante esta situación la Comisión Constitucional de las Cortes, integrada por catorce diputados y presididas por el socialista Luis Jiménez de Asúa, será la encargada de preparar un proyecto de Constitución. En tan sólo 20 días se elaboró un texto que constaba de 121 artículos, y que se daría a conocer el 27 de agosto de 1931. Poco antes de esta fecha, Azaña anotará:

«Hemos llamado (el Gobierno) a Jiménez de Asúa, Presidente de la Comisión de Constitución para acelerar la redacción del dictamen. Asúa dice que no tiene medios de imponer a la Comisión un criterio ni un método de trabajo más expeditivo... Cree que en doce o catorce días podrá estar hecho el proyecto. Convenimos que si para el lunes no está terminado, comenzará el martes, la discusión del título primero. Prieto es partidario de que se suspendan las sesiones una semana, hasta que la Comisión termine su trabajo, para impedir que las Cortes se entreguen a debates estériles o perjudiciales. Se hablará con Besteiro para que explore la opinión de los grupos.» ${ }^{25}$

Poco tardará en hacerse presente entre los miembros del Gobierno y de las Cortes las discrepancias por el proyecto presentado. Azaña trae, en esta ocasión, opiniones ajenas en torno al texto. El Ministro de la Guerra guardará su «primer silencio» frente a esta polémica:

«Maura opina que el Presidente (Alcalá-Zamora) está disgustado por el proyecto de Constitución, que estima disparatado, lo mismo en lo que es poderes del presidente, forma de elección, etc., que en la parte religiosa. Y este es el origen de la dimisión. PREVÉ LA GUERRA CIVIL POR LA CUESTIÓN RELIGIOSA -el subrayado es nuestro-, y quiere apartarse, para ser una reserva de paz. Esto es opinión de Maura.

Dicen algunos ministros que es preciso tranquilizar al Presidente ofreciéndole que estaremos a su lado para corregir los desmanes del proyecto de Constitución.

Más tarde, en el banco azul, Fernando (De los Ríos) me dice que ha hablado con el Presidente y que está "muy entregado». No me preocupa la cuestión. $\gg{ }^{26}$

Los comienzos del debate constitucional no parece que suscitaran en demasía el interés de Azaña. Dos días antes del inicio de la discusión del proyecto presentado a las Cortes, la opinión que reina en su partido, Acción Republicana, es del todo confusa y dispar. ${ }^{27}$ El día 27 de agosto, fecha de la presentación del proyecto, Azaña guardará su «segundo silencio»: 
«Ha comenzado el debate de la Constitución. Jiménez de Asúa, presidente de la Comisión, ha hecho su discurso bastante bien, pero pedantísimo, $\mathrm{y}$, en suma, superficial. ¿Qué tono, qué postura, qué modo de triplicar las erres! Mi correligionario Sánchez Albornoź ha hablado por fin en nombre del grupo de Acción Republicana. Ha gustado a los pocos diputados, que quedaban en el salón. Discreto, algo premioso, golpes de erudición histórica, castellanismo, etcétera. Nada que disuene ni nos comprometa. Ha citado seis veces lo menos a Ortega, que le oía con atención. Le han aplaudido. Menos mal.» ${ }^{28}$

La fase final del «iter» constituyente tiene lugar con la aprobación por las Cortes de un texto, que ahora cuenta con 125 artículos, el 9 de diciembre de 1931. Azaña, investido Presidente del Consejo desde octubre de ese mismo año, guardará su «tercer silencio»:

«Por la tarde se ha votado la Constitución... Esperaban quizá un discurso mío, y algunos diputados me lo han dicho después. Pero yo no he encontrado el momento oportuno, y, después de hablar Besteiro, ya no era correcto. Lo prefiero así, porque con la vida que me han dado estos días, no he tenido ni cinco minutos para pensar algo que decir, y seguramente habría estado mal; tan cansado estoy. ${ }^{29}$

Es claro pues, que a Azaña los debates constitucionales le interesaron poco, y mucho menos desde que accedió a la Presidencia del Gobierno. No le faltó razón a Alcalá-Zamora cuando escribe:

«Hubo durante aquel debate dos contrapuestas actitudes de los dos jefes de gobierno. Hasta el 13 de octubre yo no me aparté un día ni casi una hora del problema, que seguí paso a paso; desde el siguiente día 14 Azaña no volvió a ocuparse de la Constitución, entregándola al azaroso capricho de las Cortes sin guía ni consejo. Era evidente, sin embargo, que tal inhibición, sin precedentes en el mundo, conduciría a gravísimos peligros y deficiencias, cuyo estrago se ha mostrado terrible.. ${ }^{30}$

Pero pese a estas «inhibiciones», Azaña se alzará con la primacía de la oratoria parlamentaria en aquellas Cortes, pronunciando discursos que han pasado a la historia de nuestros anales políticos. Su actitud fue siempre la misma: «decir las cosas tales como son y afrontar con nuestra responsabilidad inmediata y personal nuestras propias afirmaciones». ${ }^{31}$ Quizás ahí radicó su equivocación. 
1. Marichal, Juan. La Vocación de Manuel Azaña. Alianza Editorial. Madrid, 1982. Pág. 53.

2. Nos referimos a los artículos publicados en las revistas Gente Vieja y La Avispa. También a su tesis doctoral «La Responsabilidad de la Multitudes», y a su discurso en la Real Academia de Jurisprudencia y Legislación pronunciada bajo el título de «La Libertad de Asociación».

3. Sobre la influencia de Francia en el pensamiento de Azaña, véase: La Inteligencia Republicana. Manuel Azaña 1897-1930. Biblioteca Nueva. Madrid, 1988. Págs. 35 y ss. Autor: José M. ${ }^{a}$ Marco.

4. El Problema Español. Recogida en la obra Azaña. Edición a cargo de Vicente Serrano Alberto y José M. ${ }^{a}$ Luciano. Edascal. Madrid, 1980. Pág. 40.

5. Morodo Leoncio, Raúl. Tierno Galván y otros precursores políticos. Ediciones «El País». Madrid, 1987. Pág. 40.

6. El Problema Español. Obra citada anteriormente. Pág. 33.

7. Ibid. Pags. 32 y 33.

8. Ibid. Pág. 3.

9. Ibid. Págs. 4 y 5.

10. Ibid. Pág. 10.

11. Ibid. Pág. 23.

12. Ibid. Pág. 23.

13. Ibid. Pág. 24.

14. Ibid. Pág. 28.

15. Cit. por Raymond Car. España 1808-1939. Ariel. Barcelona. Ariel, 1978. Pág. 563.

16. Azaña, Manuel. Memorias Políticas y de Guerra. Afrodisio Aguado. Madrid, 1976. Pág. 232. Vol. I.

17. Ibid. Pág. 337.

18. Cit. en Juan Marichal, La Vocación de... Pág. 129.

19. Azaña, Manuel. Antología. 1. Ensayos. Alianza Editorial. Madrid, 1982. Págs. 40 y 42.

20. Ibid. Pág. 32.

21. Ibid. Pág. 33 y ss.

22. Cit. en Azaña (ver nota 4). Pág. 230. 
23. Rama, Carlos M. La Crisis Española del siglo XX. Fondo de Cultura Económica. Madrid, 1976. Pág. 109.

24. Azaña, Manuel. Memorias... Pág. 37.

25. Ibid. Pág. 154.

26. Ibid. Págs. 173 y 174.

27. Véase a este respecto Eduardo Espín. Azaña en el poder. El partido de Acción Republicana. Centro de Investigaciones Sociológicas. Madrid, 1980. Pág. 73 y ss.

28. Azaña, Manuel. Memorias... Pág. 202.

29. Ibid. Pág. 552.

30. Alacalá-Zamora, Niceto. Memorias. Planeta. Barcelona, 1977. pág. 180.

31. Marichal, Juan. La Vocación de... Pág. 176. 